\title{
Targeted inhibition of the phosphoinositide 3-kinase impairs cell proliferation, survival, and invasion in colon cancer
}

This article was published in the following Dove Press journal:

OncoTargets and Therapy

II September 2017

Number of times this article has been viewed

\author{
Fei Yang ${ }^{1, *}$ \\ Jun-Yi Gao ${ }^{2, *}$ \\ Hua Chen' \\ Zhen-Hua Du' \\ Xue-Qun Zhang ${ }^{3}$ \\ Wei $\mathrm{Gao}^{4}$ \\ 'Department of Pathology, \\ Jinan Central Hospital Affiliated \\ to Shandong University, Jinan, \\ ${ }^{2}$ Department of Clinical Medicine, \\ Weifang Medical College, Weifang, \\ ${ }^{3}$ Graduate School, Taishan Medical \\ University, Xintai, ${ }^{4}$ Department of \\ Oncology, Jinan Central Hospital \\ Affiliated to Shandong University, \\ Jinan, People's Republic of China \\ *These authors contributed equally \\ to this work
}

Background: Colon cancer is the third most common cancer in the world, and its metastasis and drug resistance are challenging for its effective treatment. The PI3K/Akt/mTOR pathway plays a crucial role in the pathogenesis of colon cancer. The aim of this study was to investigate the targeting of PI3K in colon cancer cells HT-29 and HCT-116 in vitro.

Methods: In HT-29 and HCT-116 cells, BEZ235, a dual inhibitor of PI3K/mTOR, and shRNAtarget to PI3KCA were used to inhibit PI3K/Akt/mTOR pathway. The inhibition efficiency of PI3K/Akt/mTOR pathway was detected by RT-PCR and Western blot. Cell proliferation, migration, invasion, and apoptosis were evaluated by Cell Counting Kit-8, Transwell, and flow cytometry assays. The expression of apoptosis-related proteins (cleavage caspase 3, Bcl-2, Bax, and Bim) were also detected.

Results: We found that in HT-29 and HCT-116 cells, the treatment of BEZ235 (1 $\mu \mathrm{M})$ and PI3KCA knockdown inhibited the activation of PI3K/Akt/mTOR pathway and significantly suppressed cell proliferation, migration, and invasion of HT-29 and HCT-116 cells. In addition, we confirmed that knockdown of BEZ235 and PI3KCA induced cell apoptosis through the upregulated levels of cleavage caspase 3 and Bax and downregulated expression of Bcl-2 and Bim.

Conclusion: Our results indicated that targeted inhibition of the PI3K/Akt/mTOR pathway impaired cell proliferation, survival, and invasion in human colon cancer.

Keywords: human colon cancer, PI3K/Akt/mTOR pathway, BEZ235, PI3KCA knockdown

\section{Introduction}

Colon cancer is one of the most common cancers in the world, and the mortality rate is rising every year. In the case of metastasis, the 5-year survival rate for colon cancer patients is only $10 \% .{ }^{1}$ With the continuous study of colon cancer, its occurrence and development are found to be multi-stage, multi-step processes involving numerous signal pathways.

The targets of the $\mathrm{PI} 3 \mathrm{~K} /$ protein kinase B (Akt)/mammalian rapamycin (mTOR) are usually associated with the development of cancer, including colon cancer. ${ }^{2-5}$ This pathway is upregulated in cancers and is associated with increased proliferation, decreased apoptosis, and promoted cancer pathogenesis. ${ }^{6}$ Moreover, the activation of $\mathrm{PI} 3 \mathrm{~K} / \mathrm{Akt} / \mathrm{mTOR}$ pathway is closely related to the drug resistance of colon cancer, thus reducing the success rate of treatment. ${ }^{7,8}$ In addition, the activation of $\mathrm{PI} 3 \mathrm{~K}$ regulates various downstream proteins involved in tumor progression, such as p70S6K, cyclin D1, $\beta$-catenin, E-cad, Bcl-2/Bax, and so on. Among them, p70S6K is a substrate for $\mathrm{mTOR}$ that is regulated by $\mathrm{PI} 3 \mathrm{~K} / \mathrm{Akt} / \mathrm{mTOR}$ and related to cell proliferation,
Correspondence: Wei Gao

Department of Oncology, Jinan

Central Hospital Affiliated to Shandong

University, No.I05 Jiefang Road,

Jinan 2500 I3, Shandong, People's

Republic of China

Tel/fax +86 I53 I88I 6092

Email gjygwdr_1994@I26.com 
survival, and epithelial-mesenchymal transition (EMT). ${ }^{9,10}$ Therefore, inhibiting the PI3K/Akt/mTOR pathway may have the potential for cancer treatment and may enhance the sensitivity of chemotherapy and radiotherapy.

BEZ235 has dual inhibitory effects on PI3K and m-TOR, blocking the PI3K activity by simultaneously inhibiting mTOR. In tumor research and clinical trials, BEZ235 has been used because of its effectiveness and low side effects. ${ }^{11-14}$ A previous study showed that, even in PIK3CA mutation status, the cell proliferation of colorectal cancer cell lines (HCT116, DLD-1, and SW480) was effectively inhibited by BEZ235. ${ }^{15}$ Chen et al found that BEZ235 suppressed colon cancer cell HCT-116 proliferation, leading to cell apoptosis. ${ }^{16}$ Therefore, BEZ235 was selected as an inhibitor to investigate the effects of targeting the PI3K/Akt/mTOR pathway in colon cancer cells. shRNA transfection is a simple and effective way to knock down PI3K and PI3KCA, which is used in various cancer studies including HT-29 and HCT-116 cells. ${ }^{17-19}$ In the present study, we determined to explore the effects of targeted inhibition of PI3K on proliferation, migration, invasion, and apoptosis of colon cancer cells.

\section{Methods and materials Cell culture}

The colon cancer HT-29 and HCT-116 cell lines were purchased from China Cell Bank (Shanghai, China) and cultured at $37^{\circ} \mathrm{C}$ with $5 \% \mathrm{CO}_{2}$ in DMEM medium (Thermo Fisher Scientific, Waltham, MA, USA) containing 10\% fetal bovine serum (FBS) (Thermo Fisher Scientific), $100 \mathrm{U} / \mathrm{mL}$ penicillin, and $100 \mathrm{mg} / \mathrm{mL}$ streptomycin (Thermo Fisher Scientific). The cells in the logarithmic phase with the sound condition were used for further detection. When the cells were in the total growth phase, they were divided into three groups and treated under three culture conditions: BEZ235, shRNA transfection, and dimethyl sulfoxide (DMSO) as negative control.

\section{Inhibition of PI3K/Akt/mTOR by BEZ235}

Different concentrations of BEZ235 (Cell Signaling Technology, Beverly, MA, USA; dissolved in DMSO), the specific inhibitor of PI3K/Akt pathway, were used to inhibit the PI3K/Akt/mTOR pathway based on the manufacturer's instruction. Approximately $5 \times 10^{6} \mathrm{HT}-29 / \mathrm{HCT}-116$ cells were seeded in a 6-cm diameter dish with DMEM and cultured at $37^{\circ} \mathrm{C}$ with $5 \% \mathrm{CO}_{2}$ for 24 hours. Then, the cells treated with BEZ235 at 0, $1 \mathrm{nM}, 10 \mathrm{nM}, 100 \mathrm{nM}$, and $1 \mu \mathrm{M}$ were incubated shortly thereafter for 24 hours. The appropriate concentrations of BEZ235 which achieved the maximum inhibition effect were selected for further experiments. DMSO was used as a control reagent. This experiment was repeated independently at least two times.

\section{Knockdown of PI3KCA by shRNA transfection}

We designed and synthetized the PI3KCA-shRNA as follows: shRNA (GCATTAGAATTTACAGCAAGA). The target vector pLVX-shRNA2 (Clontech Co. CA, US) was digested by BamHI and EcoRI. According to the study of Dang et al, ${ }^{20}$ the shRNA vector was constructed and transfected into HT-29 and HCT-116 cells by Liposomes 2000 (Thermo Fisher Scientific) according to the manufacturer's instructions. The transfection efficiency for HT-29 and HCT- 116 cells was $81 \%$ and $85 \%$, respectively. Forty-eight hours after transfection, the cells were collected for RT-PCR, Western blotting analysis, and other assays.

\section{Real-time quantitative RT-PCR analysis}

The mRNA level of PI3KCA was quantitatively estimated by real-time quantitative RT-PCR, to determine a definitive measurement of PI3KCA knockdown efficiency. Total RNA was isolated by RNeasy kit (Sigma, St Louis, MO, USA). Reverse transcription reactions were performed by using the PrimeScript ${ }^{\circledR} 1$ st strand cDNA synthesis kit (TaKaRa, Beijing, China). SYBR Green qPCR Master Mix (2×) kit (Thermo Fisher Scientific) was performed to analyze real-time RT-PCR with the following program: $95^{\circ} \mathrm{C} 10$ minutes, $95^{\circ} \mathrm{C} 15 \mathrm{sec}-$ onds, $60^{\circ} \mathrm{C} 60$ seconds for annealing and extension, with a repetition of 40 cycles. Real-time RT-PCR data were analyzed by comparative $\mathrm{Ct}(\Delta \Delta \mathrm{ct})$ method. The expression level of PI3KCA mRNA was normalized to an endogenous control, GAPDH. Primer sequences were as follows: PI3KCA: forward primer 5'-CAATCGGTGACTGTGTGGGA-3', reverse primer 5'-ACAGGTCAATGGCTGCATCA-3'; GAPDH: forward primer 5'-CATGAGAAGTATGACAACAGCCT-3', reverse primer 5'-AGTCCTTCCACGATA CCAAA GT-3'.

\section{Western blotting}

The expression of PI3K/Akt/mTOR-related proteins and proteins associated with apoptosis was determined by Western blotting method. HT-29 and HCT-116 cells were treated with BEZ235 at different concentrations $(0,1 \mathrm{nM}, 10 \mathrm{nM}, 100 \mathrm{nM}$, and $1 \mu \mathrm{M}$ ) for 24 hours to detect inhibition efficiency. HT-29 and HCT-116 cells were then treated with $1 \mu \mathrm{M}$ BEZ235 or transfected with PI3KCA shRNA transfection, respectively. Both the treatments lasted for 24 hours. The cells were then collected to extract proteins, which were quantified using a 
BCA Protein Assay Kit. Proteins were then separated with $10 \%$ sodium dodecyl sulfate-polyacrylamide gel electrophoresis (SDS-PAGE) and transferred to nitrocellulose membranes. After blocking with 5\% nonfat dry milk in Tris-buffered saline, $0.1 \%$ Tween 20 (TBST) for 1 hour, membranes were incubated with the primary antibody $(1: 1,000)$ at $4{ }^{\circ} \mathrm{C}$ overnight. After washing, secondary antibodies were applied to membranes and incubated at room temperature for 1 hour. Labeled protein bands were exposed using electro-chemiluminescence (ECL) solution. For quantification analyses, Western blotting was repeated for three times. The band intensity was measured by using ImageJ. The relative expression levels of proteins were calculated by standardized the band intensity with the amount of $\beta$-tubulin from the same sample.

\section{Cell proliferation assay}

According to the manufacturer's instructions, Cell Counting Kit-8 (CCK8; Dojindo, Japan) was adopted to quantify the cell proliferation after treatment with BEZ235 and PI3KCA knockdown. HT-29 and HCT-116 cells were treated with $1 \mu \mathrm{M}$ BEZ235 and shRNA transfection for 24 hours, respectively. Then, the cells were seeded in 96-well plates at a density of 1,000 cells/well and were constantly cultured with BEZ235 in normal medium. The supernatant was replaced with $100 \mathrm{~mL}$ of medium containing $10 \mathrm{~mL}$ of CCK8, enabling detection of optical density (OD) values at $450 \mathrm{~nm}$ every 24 hours.

For colony formation assays, 200 HT-29 and HCT-116 cells of three groups with 24-hour treatment of BEZ235, PI3KCA shRNA transfection, and respective NC were seeded in a disposable dish and cultured in a medium containing $10 \%$ FBS for 1 week. Colonies were fixed with methanol, stained with $0.1 \%$ crystal violet, and photographed and counted with an inverted microscope. Each treatment was performed three times.

\section{Cell migration and invasion assay}

Transwell chamber model was performed to measure cell migration and invasion after treatment with BEZ235 and PI3KCA shRNA transfection.

\section{Migration}

HT-29 and HCT-116 cells with 24-hour treatment of $1 \mu \mathrm{M}$ BEZ235 and PI3KCA shRNA transfection were suspended at a concentration of $3 \times 10^{4}$ cells $/ \mathrm{mL}$. $100 \mu \mathrm{L}$ of the suspension was added into the upper chamber of Transwell apparatus (EMD Millipore, Billerica, MA, USA; $0.8 \mu \mathrm{m}$ ). After incubation for 24 hours, we removed the cells that remained in the top chamber.

\section{Invasion}

Matrigel (BD Biosciences, San Jose, CA, USA) was used to coat the upper chambers, and the cells with the BEZ235 or PI3KCA shRNA transfection treatment were added to the upper chamber at a density of $5 \times 10^{4}$ cells/chamber $(100 \mu \mathrm{L})$. $100 \mu \mathrm{L}$ of medium with $10 \%$ FBS was added into the lower chamber. After incubation for 24 hours, cells that attached to the lower chamber were fixed in $4 \%$ paraformaldehyde and stained with $0.1 \%$ crystal violet to quantify cell migration. The Transwell assays were repeated three times.

\section{Cell apoptosis assay}

HT-29 and HCT-116 cells were seeded in six well plates and treated with BEZ235 and PI3KCA shRNA transfection at the logarithmic growth phase. After 48 hours of incubation, cells were collected at the concentration of $10^{5} / \mathrm{mL}$ in binding buffer and stained with $5 \mu \mathrm{L}$ Annexin V fluorescein isothiocyanate (FITC) and $10 \mu \mathrm{L}$ propidium iodide (PI) (BD Biosciences). Flow cytometry was then performed to assess apoptosis. The experiment was repeated three times.

\section{Statistical analysis}

The quantitative experimental data were presented as mean \pm SD and analyzed by SPSS 16.0 statistical software with one-way analysis of variance and unpaired $t$-test to analyze the differences between groups. $P<0.05$ for the difference was statistically significant.

\section{Results \\ BEZ235 effectively inhibited PI3K/Akt/ mTOR activation in HT-29 and HCT- II 6 cells}

To establish a suitable dose of BEZ235 on PI3K/Akt/ mTOR pathway, HT-29 and HCT-116 cells were treated with BEZ235 at $0,1 \mathrm{nM}, 10 \mathrm{nM}, 100 \mathrm{nM}$, or $1 \mu \mathrm{M}$. Indeed, we found that BEZ235 efficiently decreased p-Akt levels in a dose-dependent manner. As $1 \mu \mathrm{M}$ of BEZ235 had the greatest inhibitory effect, this concentration was used in the subsequent experiments (Figure 1A). The levels of p-Akt and p-mTOR in HT-29 and HCT-116 cells decreased when compared with the control groups (Figure 1B).

\section{Inhibition of $\mathrm{PI3K} / \mathrm{Akt} / \mathrm{mTOR}$ by BEZ235 resulted in a decline in HT-29 and HCT- II 6 cell proliferation}

In order to describe the BEZ235 effect on proliferative activity of HT-29 and HCT-116, after treating with $1 \mu \mathrm{M}$ of BEZ235, 
A

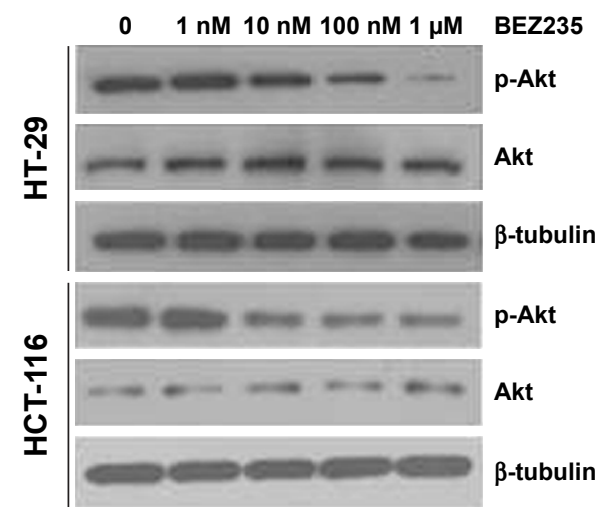

B

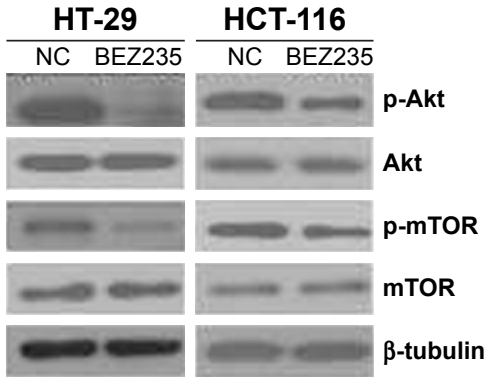

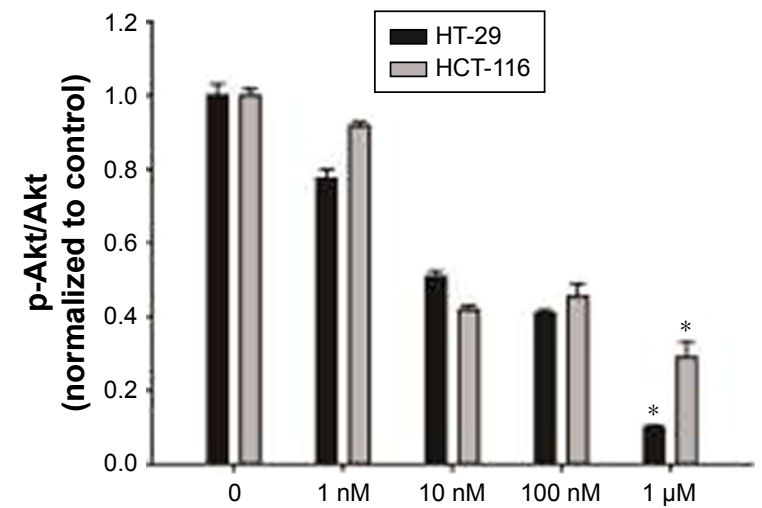

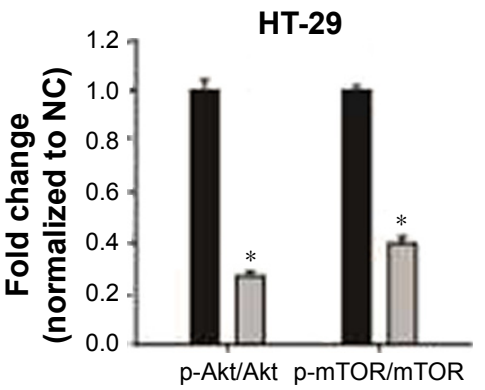

HCT-116

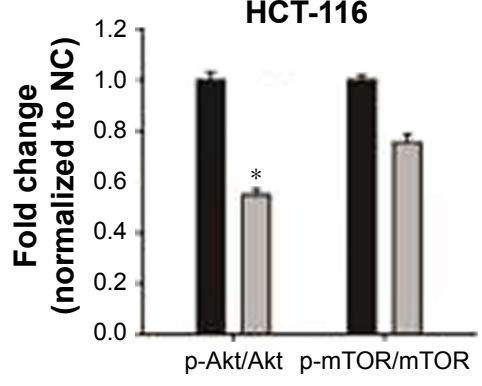

NC $\square$ BEZ235

C

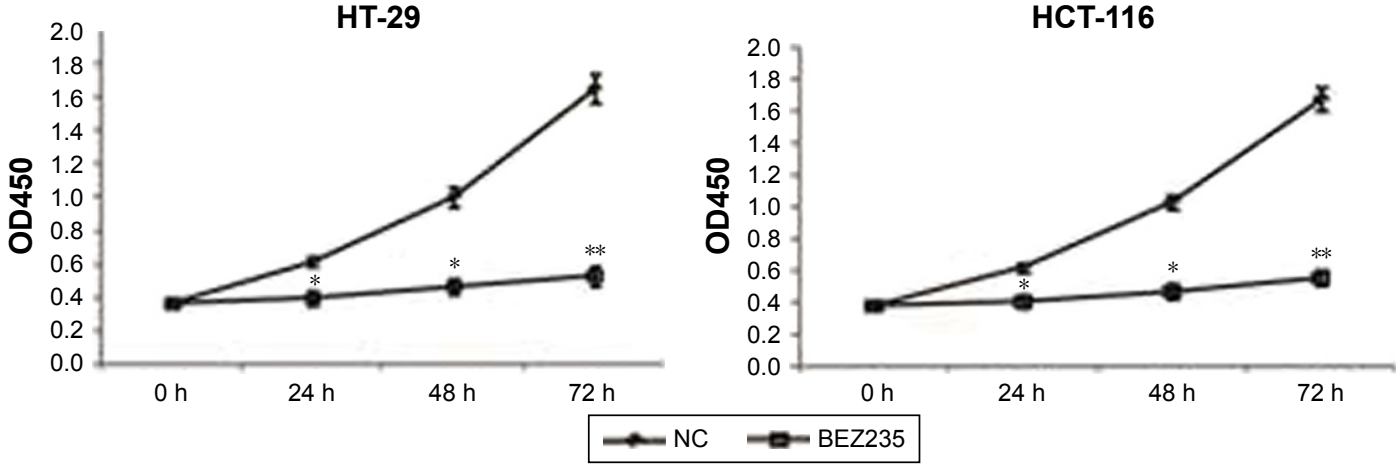

D
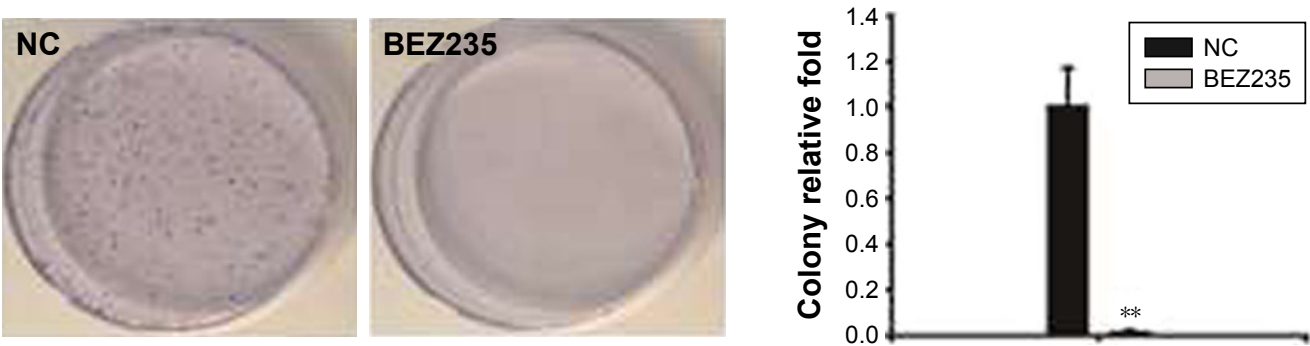

E
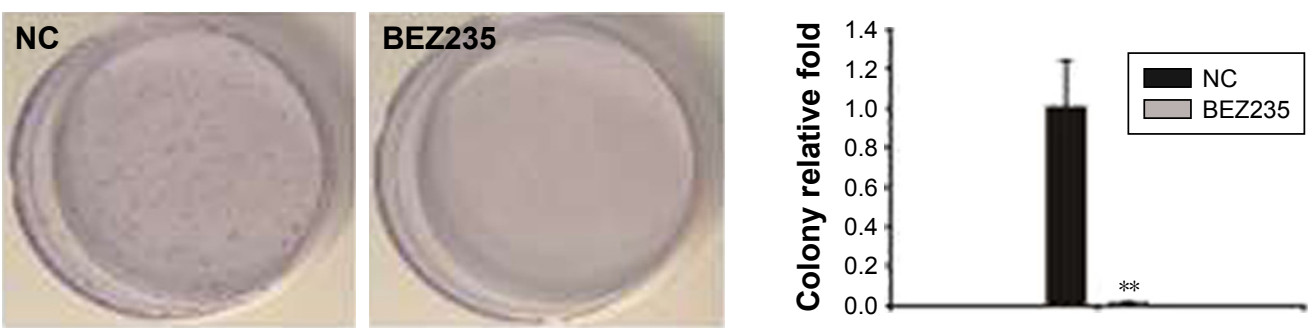

Figure I BEZ235 inhibited cell proliferation of HT-29 and HCT-II6 cells.

Notes: (A) Western blotting results showed that BEZ235 inhibited p-Akt expression, and I $\mu$ M BEZ235 had the most inhibition. (B) Western blotting results demonstrated that BEZ235 inhibited the activation of Akt and mTOR. (C) Cell Counting Kit-8 assay showed that BEZ235 significantly inhibited HT-29 and HCT-II6 cell proliferation at 24, 48, and 72 hours. (D) Colony formation assays showed that BEZ235 inhibited the colony formation of HT-29 cells. (E) BEZ235 inhibited colony formation of HCT-II6 cells. $* P<0.05$ and $* * P<0.00$ I versus control.

Abbreviations: OD450, optical density $450 \mathrm{~nm} ; \mathrm{NC}$, negative control. 
the cell viability was detected with CCK8 and colony formation assay. The proliferation of HT-29 and HCT-116 cells was significantly inhibited by BEZ235 in 24 hours (Figure 1C). Compared with the control group, the proliferation ability of cells increased significantly during the treatment period. Similar results were observed in the analysis of colony formation. BEZ235 inhibition of the PI3K/Akt/mTOR pathway led to a significant reduction in the number of cell colonies of HT-29 and HCT-116 cells, compared with the control group (Figure 1D and E).

\section{PI3KCA knockdown reduced HT-29 and HCT-I I 6 cell proliferation}

To confirm the inhibitory effect of the PI3K/Akt/mTOR pathway on colon cancer cells, PI3KCA shRNA transfection was used to inhibit PI3KCA expression. In knockdown HT-29 cells, the expression of PI3KCA mRNA was reduced by $70 \%$, while the knockdown of HCT-116 cells decreased by $68 \%$. The cells were detected by RT-PCR and compared with control cells of 48 hours past-transfection (Figure 2A). In knockdown HT-29 and HCT-116 cells, the PI3K/Akt/ mTOR pathway activation was also significantly suppressed (Figure 2B and C). PI3KCA knockdown resulted in a significant decrease in the proliferation of HT-29 and HCT-116 cells at the time of 48 and 72 hours, respectively (Figure 2D), compared to the control group. These results were also confirmed by colony formation assays. Compared with the control group, the number of cells in the PI3KCA-knockdown HT-29 cell group decreased by $>93 \%$ (Figure $2 \mathrm{E}$ ), while the PI3KCAknockdown HCT-116 cells (Figure 2F) decreased by 92\%.

\section{Inhibition of PI3K/Akt/mTOR suppressed migration and invasion of HT-29 and HCT-I I 6 cells}

In order to investigate the effect of inhibiting PI3K/Akt/ mTOR pathway on HT-29 and HCT-116 cell migration and invasion, a Transwell assay was carried out. PI3K/Akt/ mTOR inhibition by BEZ235 and PI3KCA knockdown both resulted in a migration rate through an $8 \mu \mathrm{m}$ polycarbonate membrane filter dropped by $73 \%$ and $58 \%$ on HT-29 cell and HCT-116 cell migration rates were reduced to $68 \%$ and 55\%, respectively (Figure 3A). The Transwell invasion assay showed that BEZ235 and PI3KCA knockdown both significantly decreased cell invasion in HT-29 (75\%, 63\%) and HCT-116 (72\%, 60\%) cells (Figure 3B).

\section{Inhibition of $\mathrm{PI} 3 \mathrm{~K} / \mathrm{Akt} / \mathrm{mTOR}$ induced HT-29 and HCT-I I 6 cell apoptosis in vitro}

To further evaluate the inhibitory effects of PI3K/Akt/mTOR by BEZ235 and PI3KCA knockdown on cell apoptosis, flow cytometry assay and Western blotting were performed. As shown in Figure 4A, 16\% of apoptotic cells were found in the negative control group, but the proportions of apoptotic cells in HT-29 cells were significantly increased to $35 \%$ and $26 \%$ with treatment of BEZ235 and PI3KCA knockdown, respectively. In HCT-116 cells, BEZ235 treatment and PI3K knockdown also promoted apoptosis (Figure 4A). The expression levels of proteins associated with apoptosis changed, with the expression of cleavage caspase 3 and Bax increasing while $\mathrm{Bcl}-2$ and Bim decreasing significantly (Figure 4B).

\section{Discussion}

Colon cancer is the third most common cancer in the world and has not yet been adequately treated. ${ }^{21}$ Current clinical routine treatment for colon cancer includes surgical resection of primary tumor, chemotherapy, radiotherapy, and immunotherapy, with limitations and side effects. Drug resistance also affects the treatment efficacy. ${ }^{22,23}$ The PI3K/Akt/mTOR pathway is closely related to the pathogenesis and process of cancer and is involved in drug resistance..$^{3-8}$ Therefore, inhibition of PI3K/Akt/mTOR signaling pathway may be of great significance to the treatment of cancer.

Activated Akt will promote cell growth and survival by inhibiting the pro-apoptotic proteins of Bcl-2 family. ${ }^{24} \mathrm{mTOR}$ is a serine/threonine kinase that can be induced by the activity of activated Akt. ${ }^{25}$ Activated mTOR is involved in gene transcription and protein translation. It has been proven that Akt and mTOR have strong expression in colon cancer tissue and HT-29 cells. ${ }^{26}$ The PI3K/Akt/mTOR pathway is a crucial regulator in cell growth, including proliferation, growth, differentiation, and survival. Therefore, abnormal activation of $\mathrm{PI} 3 \mathrm{~K} / \mathrm{Akt} / \mathrm{mTOR}$ signaling pathway is commonly involved in the development and progression of various tumors. ${ }^{27-31}$ $\mathrm{PI} 3 \mathrm{~K} / \mathrm{Akt} / \mathrm{mTOR}$ signaling pathway is upregulated and plays an important role in colon cancer..$^{2-4,32,33}$ In addition, a large number of studies have shown that this pathway is also related to drug resistance. ${ }^{2,5-7}$ Thus, targeting the PI3K/Akt/ mTOR pathway may be a promising technique for treating colon cancer.

BEZ235 is a novel dual inhibitor of both PI3K and mTOR and has been used in many research studies. ${ }^{29}$ Several previous reports in these studies suggested that, in the form of apoptosis or autophagy in tumors, the treatment of BEZ235 can inhibit cell proliferation and induce cell death autophagy. ${ }^{11-14,34}$ It has been proven that BEZ235 suppresses HCT-116 cell proliferation. ${ }^{16}$ Hong confirmed that by inducing apoptosis, BEZ235 has inhibitory effects on HT-29 and HCT-116. ${ }^{35}$ In our studies, we found that 
A

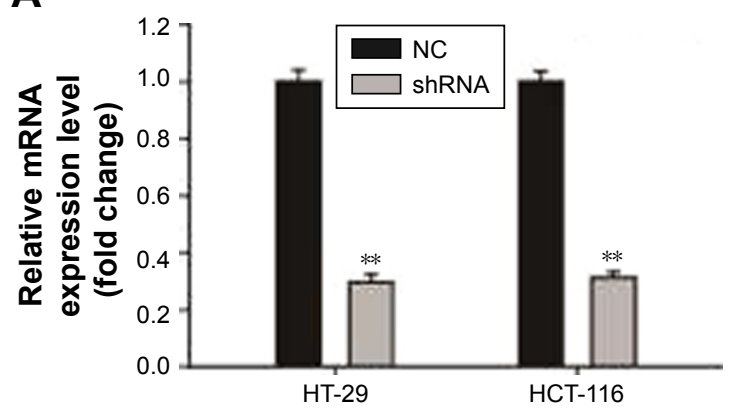

C

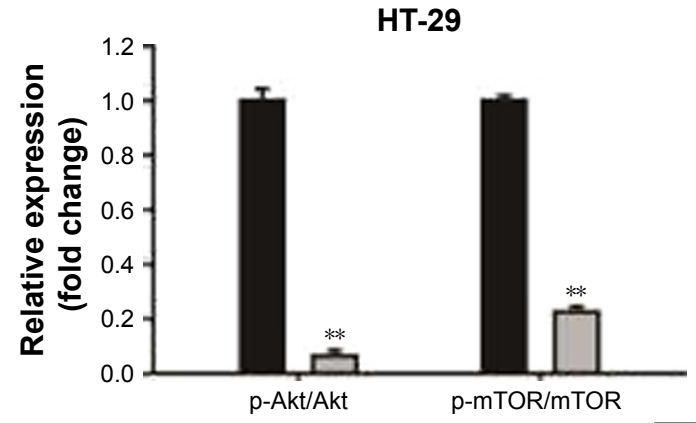

B

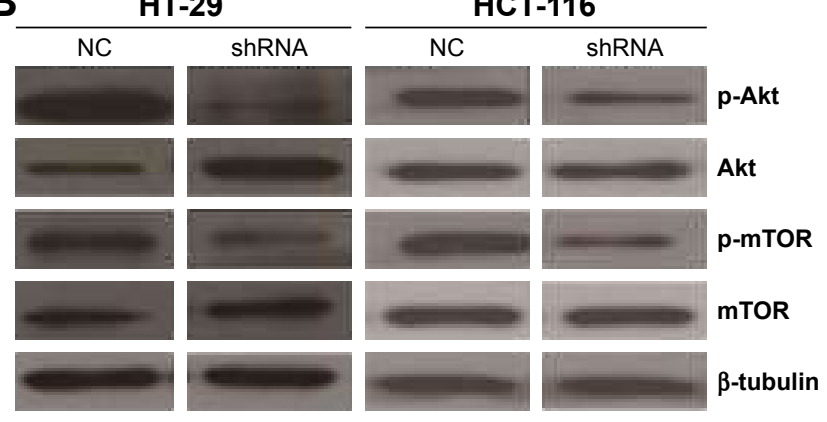

HCT-116

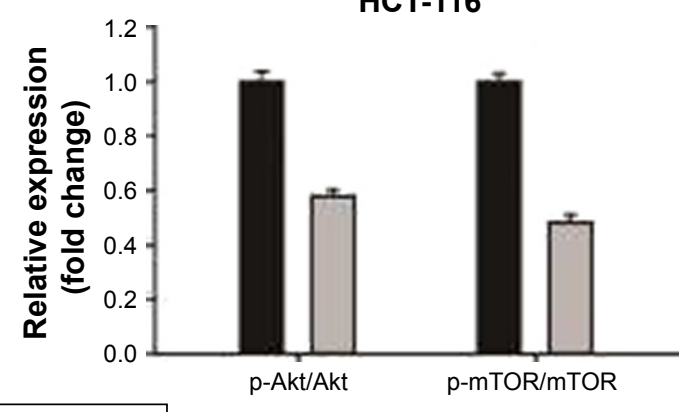

NC $\square$ shRNA

D

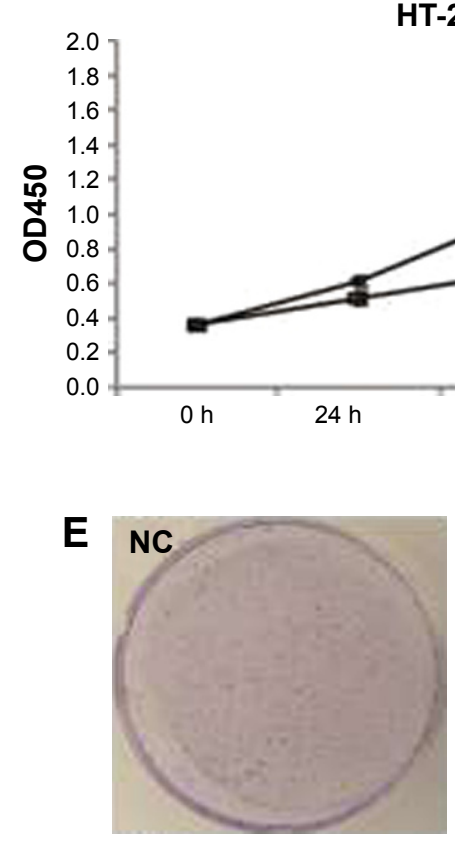

F

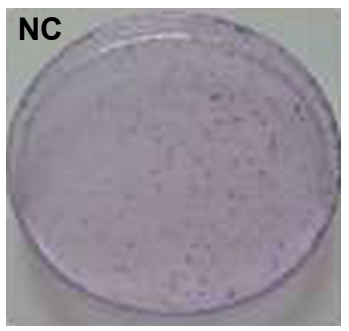

HT-29

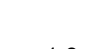

HCT-116

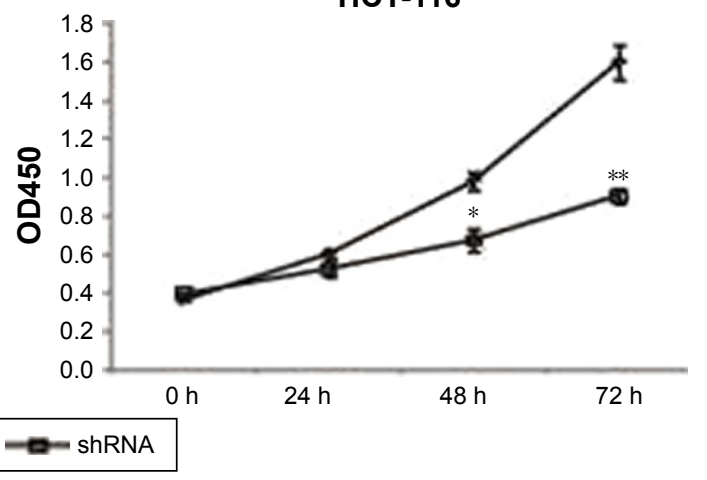

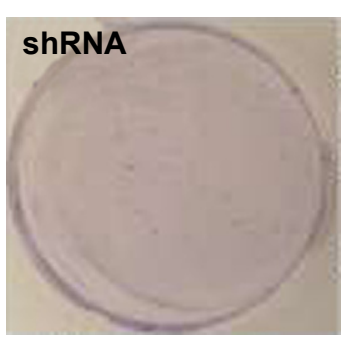
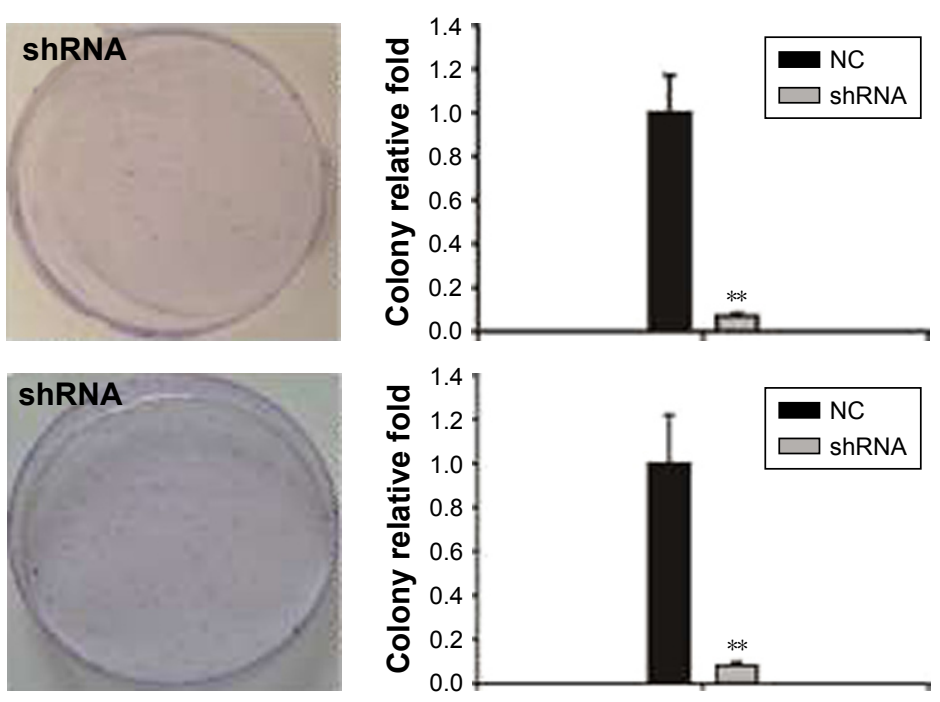

Figure 2 PI3KCA knockdown inhibited proliferation of HT-29 and HCT-I 16 cells.

Notes: (A) RT-PCR result showed that the expression of PI3KCA mRNA was significantly inhibited after shRNA transfection. (B) Western blotting results showed that shRNA transfection inhibited the activation of Akt and mTOR. (C) The quantitative analysis of Western blotting result. (D) Cell Counting Kit-8 assay showed that PI3KCA knockdown significantly inhibited the proliferation of HT-29 and HCT-II6 cells. (E) Colony formation assays showed that colony formation was inhibited in PI3KCAknockdown HT-29 cells. (F) PI3KCA knockdown inhibited the colony formation of HCT-II 6 cells. $* P<0.05$ and $* * P<0.001$ versus control.

Abbreviations: OD450, optical density $450 \mathrm{~nm}$; NC, negative control. 
A
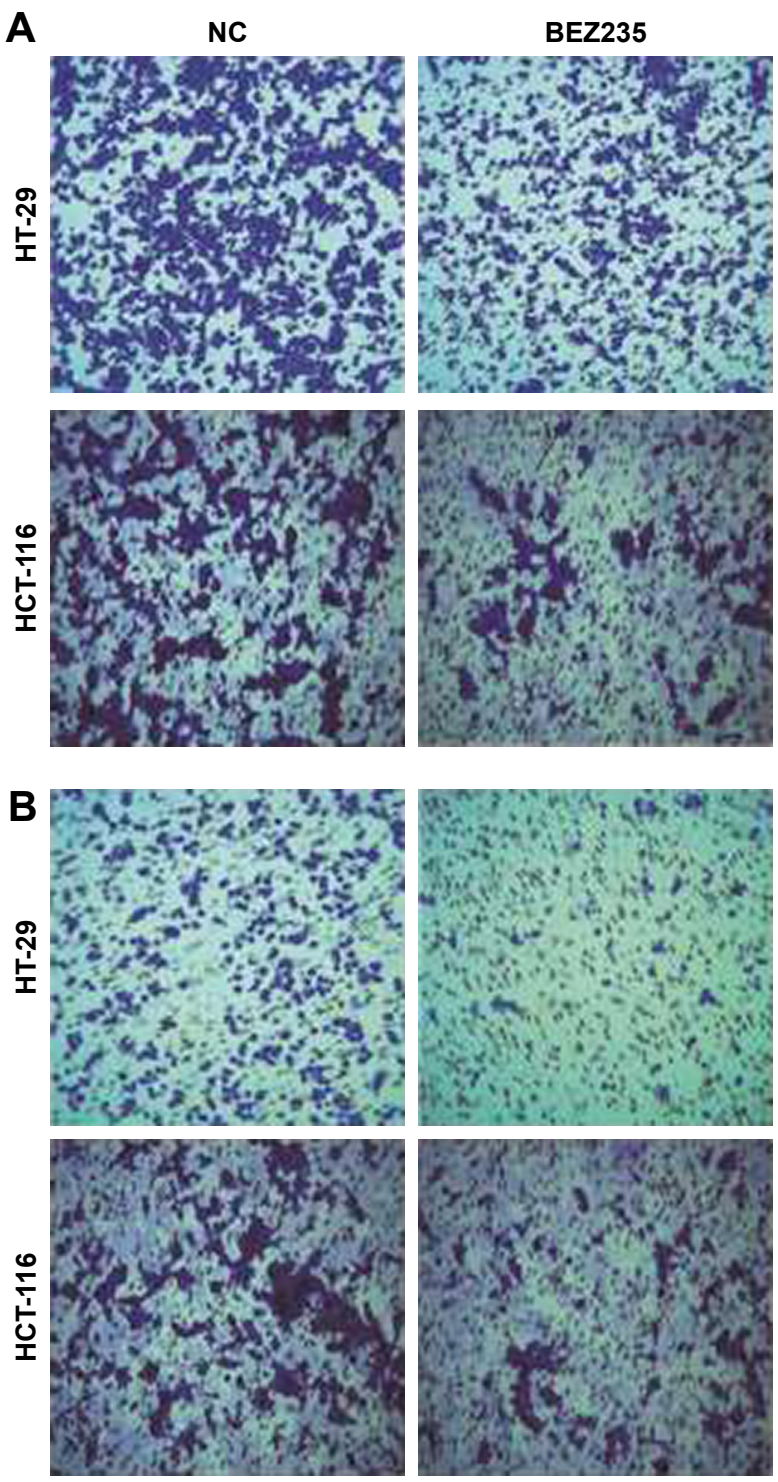
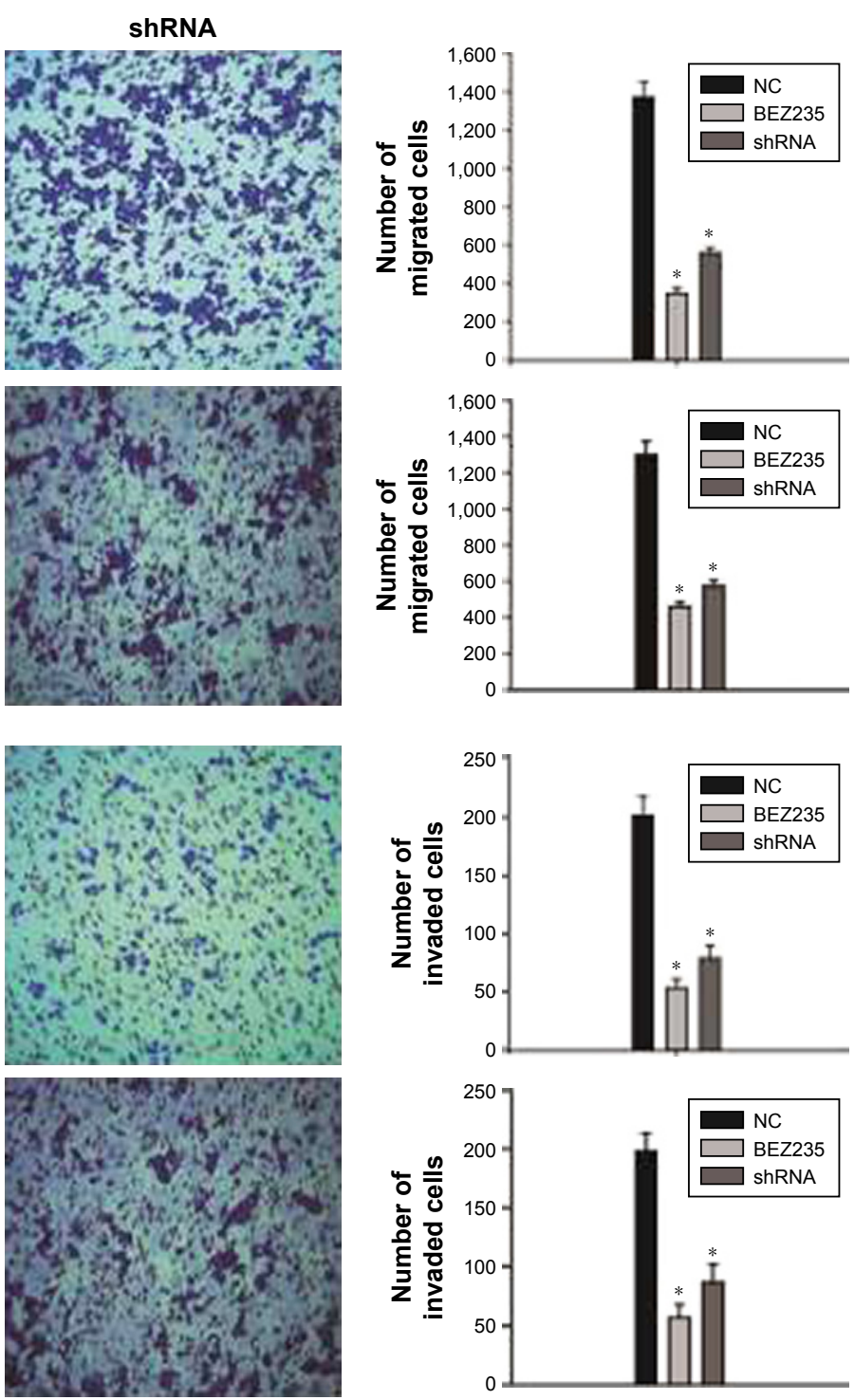

Figure 3 Inhibition of PI3K/Akt/mTOR pathway by BEZ235 and PI3KCA knockdown resulted in decreased cell migration and invasion.

Notes: (A) Transwell assay showed that cell migration of HT-29 and HCT-I I6 were obviously inhibited by BEZ235 and PI3KCA knockdown. (B) Cell invasion of HT-29 and HCT-II 6 were significantly inhibited by BEZ235 and PI3KCA knockdown. $* P<0.05$ versus control.

Abbreviation: NC, negative control.

BEZ235 can effectively inhibit the activation of PI3K/Akt/ mTOR pathway, cell proliferation, migration, invasion, and induced apoptosis in HT-29 and HCT-116 cells (Figures 1, 3, and 4). Inhibition of PI3K/Akt/mTOR pathway by PI3KCA knockdown can also reduce cell proliferation, migration, invasion, and induced apoptosis (Figures 2-4). Therefore, inhibition of PI3K/Akt/mTOR pathway may significantly inhibit cell progression in colon cancer.

Caspase 3 is a key member of the cysteine-aspartic acid protease family, an important protease that causes apoptosis. ${ }^{36} \mathrm{Bcl}-2$ and Bax are important regulators of apoptosis, involved in the regulation of cell death. ${ }^{37} \mathrm{Bcl}-2$ is an antiapoptosis protein that is localized in mitochondria, while Bax is a pro-apoptotic protein that mainly resides in the cytoplasm. The ratio of Bcl-2/Bax determines cell survival, as a reduction in the ratio promotes cell apoptosis. ${ }^{38,39} \mathrm{Bim}$ (cell death mediated by Bcl-2) is another important member of the Bcl-2 family and has a similar role to Bax in promoting cell apoptosis. ${ }^{40}$ The present study shows that through a downregulation process of Bcl-2 and Bim expressions, inhibition of PI3K/Akt/mTOR pathway by BEZ235 and PI3KCA knockdown induced HT-29 and HCT-116 cells apoptosis, at the same time keeping an upregulation in cleavage caspase 3 and Bax (Figure 4B).

In summary, this study reveals that targeted inhibiting PI3K/Akt/mTOR pathway by BEZ235 and PI3KCA knockdown could inhibit cell proliferation, survival, and invasion in human colon cancer. Therefore, in addition to surgery, 
A

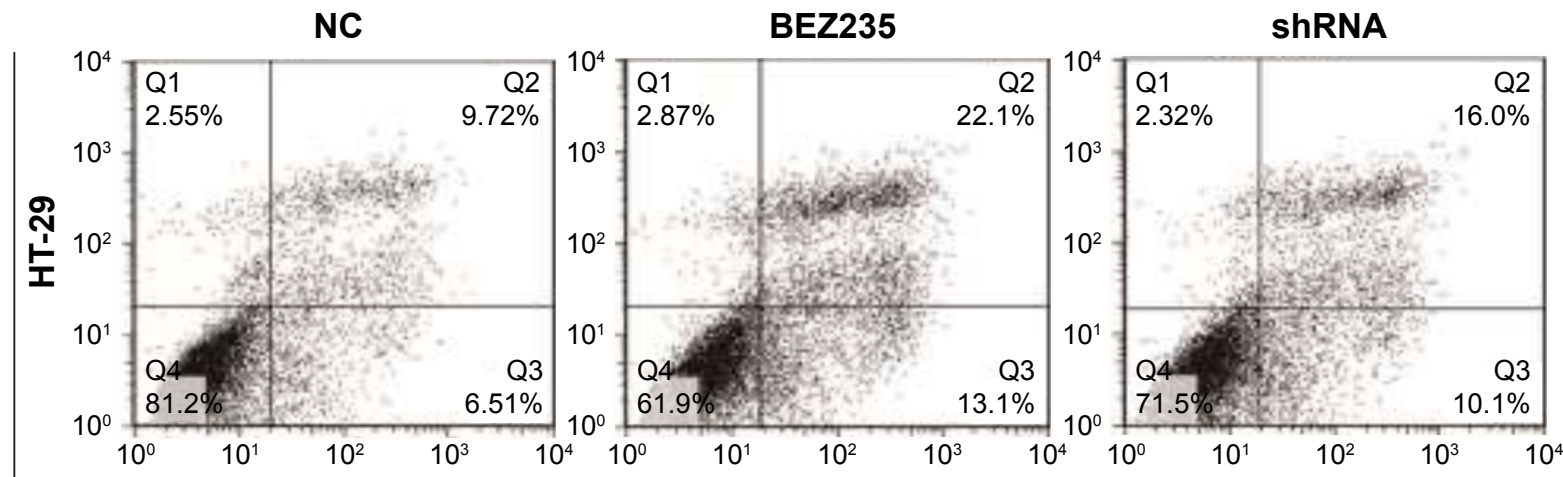

PI
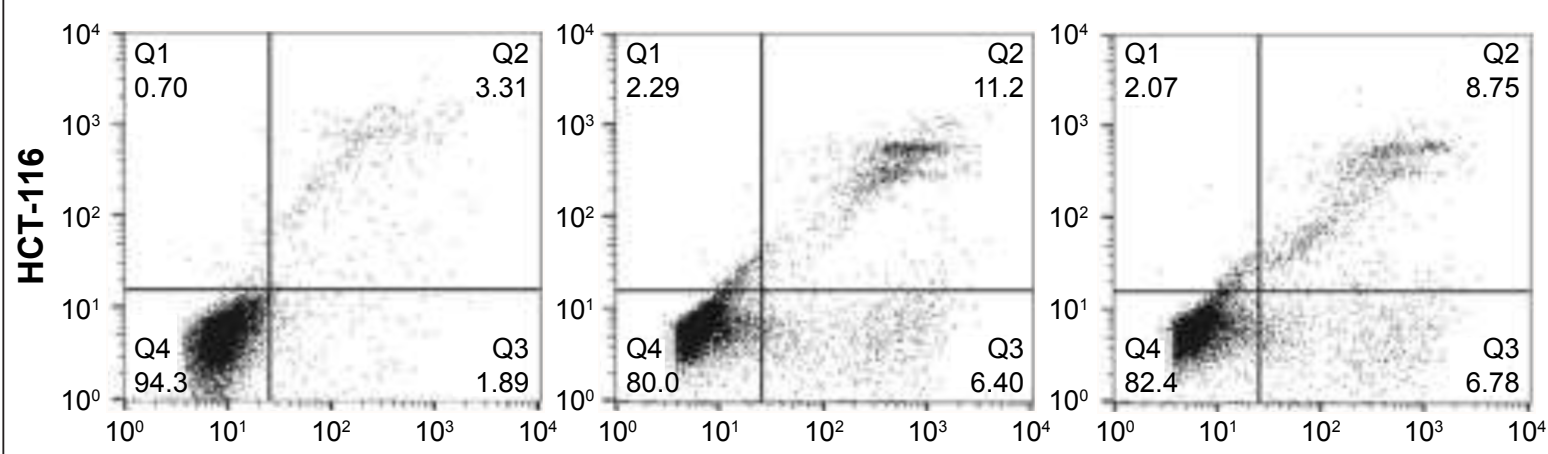

Annexin V FITC

B

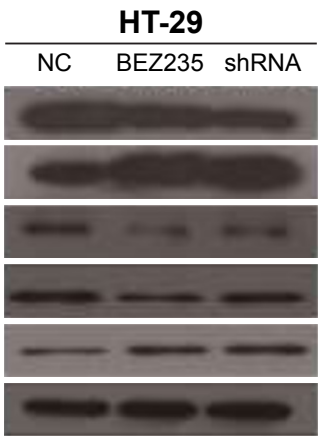

HCT-116

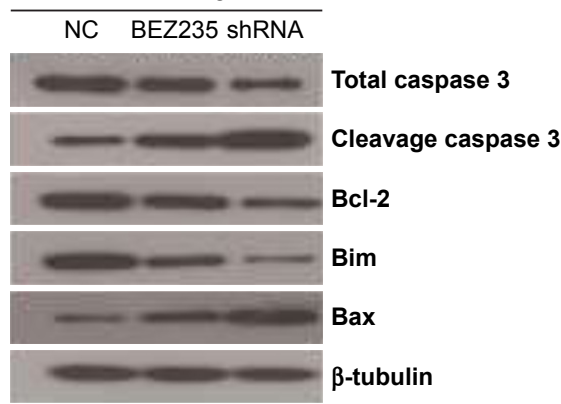

HT-29
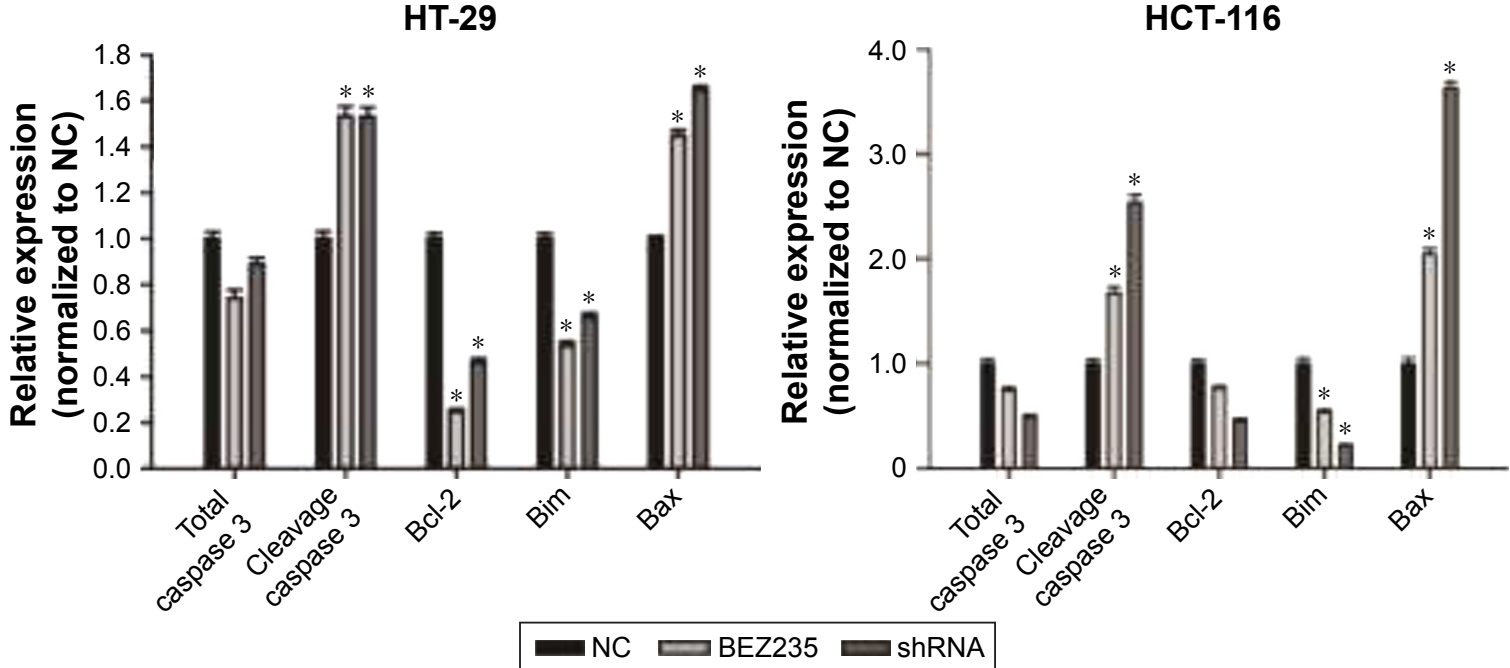

Figure 4 Inhibition of PI3K/Akt/mTOR pathway by BEZ235 and PI3KCA knockdown induced cell apoptosis.

Notes: (A) Flow cytometry assay showed that cell apoptosis of HT-29 and HCT-II6 were induced by BEZ235 and PI3KCA knockdown. (B) Western blotting results showed that BEZ235 treatment and PI3KCA knockdown inhibited $\mathrm{Bcl}-2$ and Bim expression and induced cleavage caspase 3 and $\mathrm{Bax}$ expression. *P $<0.05$ versus controls. Abbreviations: FITC, fluorescein isothiocyanate; NC, negative control; PI, propidium iodide. 
chemotherapy, and radiotherapy, targeted inhibiting PI3K/ $\mathrm{Akt} / \mathrm{mTOR}$ pathway may be a valuable technique for human colon cancer therapy.

\section{Acknowledgment}

This work was supported by the Science and Technology Plan of Shandong (Grant No 2014GSF118008).

\section{Disclosure}

The authors report no conflicts of interest in this work.

\section{References}

1. Davies JM, Goldberg RM. Treatment of metastatic colorectal cancer. Semin Oncol. 2011;38:552-560.

2. Chen J. Potential value and limitation of dual inhibitors of PI3K and mTOR in the treatment of cancer. Curr Cancer Drug Targets. 2013; 13:117-120.

3. Bu Z, Ji J. Therapeutic implications of mTOR inhibitors in the treatment of gastric cancer. Curr Cancer Drug Targets. 2013;13:121-125.

4. Cho DC, Mier JW. Dual inhibition of PI3-kinase and mTOR in renal cell carcinoma. Curr Cancer Drug Targets. 2013;13:126-142.

5. Elfiky AA, Jiang Z. The PI3 kinase signaling pathway in prostate cancer. Curr Cancer Drug Targets. 2013;13:157-164.

6. Yu Y, Yu X, Ma J, Tong Y, Yao J. Effects of NVP-BEZ235 on the proliferation, migration, apoptosis and autophagy in HT-29 human colorectal adenocarcinoma cells. Int J Oncol. 2016;49:285-293.

7. Chen J, Iverson D. Estrogen in obesity-associated colon cancer: friend or foe? Protecting postmenopausal women but promoting late-stage colon cancer. Cancer Causes Control. 2012;23:1767-1773.

8. Wang H, Zhang L, Yang X, et al. PUMA mediates the combinational therapy of 5-FU and NVP-BEZ235 in colon cancer. Oncotarget. 2015; 6:14385-14398.

9. Wu D, Cheng J, Sun G, et al. p70S6K promotes IL-6-induced epithelialmesenchymal transition and metastasis of head and neck squamous cell carcinoma. Oncotarget. 2016;7:36539-36550.

10. Segatto I, Berton S, Sonego M, et al. p70S6 kinase mediates breast cancer cell survival in response to surgical wound fluid stimulation. Mol Oncol. 2014;8:766-780.

11. Ji Y, Di W, Yang Q, Lu Z, Cai W, Wu J. Inhibition of autophagy increases proliferation inhibition and apoptosis induced by the PI $3 \mathrm{~K} / \mathrm{mTOR}$ inhibitor NVP-BEZ235 in breast cancer cells. Clin Lab. 2015;61: 1043-1051.

12. Li C, Xin P, Xiao H, Yan Z, Huang Y, Zhu X. The dual PI3K/mTOR inhibitor NVP-BEZ235 inhibits proliferation and induces apoptosis of burkitt lymphoma cells. Cancer Cell Int. 2015;15:65.

13. Maira SM, Stauffer F, Brueggen J, et al. Identification and characterization of NVP-BEZ235, a new orally available dual phosphatidylinositol 3-kinase/mammalian target of rapamycin inhibitor with potent in vivo antitumor activity. Mol Cancer Ther. 2008;7:1851-1863.

14. Wang W, Long L, Yang N, et al. NVP-BEZ235, a novel dual $\mathrm{PI} 3 \mathrm{~K} / \mathrm{mTOR}$ inhibitor, enhances the radiosensitivity of human glioma stem cells in vitro. Acta Pharmacol Sin. 2013;34:681-690.

15. Roper J, Richardson MP, Wei VW, et al. The dual PI3K/mTOR inhibitor NVP-BEZ235 induces tumor regression in a genetically engineered mouse model for sporadic colorectal cancer. Gastroenterology. 2011;6:e25132.

16. Chen J, Shao R, Li F, et al. PI3K/Akt/mTOR pathway dual inhibitor BEZ235 suppresses the stemness of colon cancer stem cells. Clin Exp Pharmacol Physiol. 2016;42:1317-1326.

17. Yan F, Shao LJ, Hu XY. Knockdown of UHRF1 by lentivirus-mediated shRNA inhibits ovarian cancer cell growth. Asian Pac J Cancer Prev. 2015;16:1343-1348.
18. Habib R, Akhtar J, Taqi M, Yu C, Zhang C. Lentiviral vector-mediated survivin shRNA delivery in gastric cancer cell lines significantly inhibits cell proliferation and tumor growth. Oncol Rep. 2015;34:859.

19. Gayatri DV, Badana A. Therapeutic Potentials of CD151 shRNA in Targeting Metastasis of Triple Negative Breast Cancer Cell Line MDAMB-231. J Cancer Sci Ther. 2016;8:104-112.

20. Dang N, Pang S, Song H, An L, Ma X. Inactivation of mitogen-activated protein kinase signaling pathway reduces caspase-14 expression in impaired keratinocytes. Iran J Basic Med Sci. 2016;19:28-33.

21. Catalano V, Di FS, Iovino F, Dieli F, Stassi G, Todaro M. CD133 as a target for colon cancer. Expert Opin Ther Targets. 2012;16:259-267.

22. Chen J, Huang XF, Qiao L, Katsifis A. Insulin caused drug resistance to oxaliplatin in colon cancer cell HT29. J Gastrointest Oncol. 2011; 2:27-33.

23. Dallas NA, Ling X, Fan F, et al. Chemoresistant colorectal cancer cells, the cancer stem cell phenotype and increased sensitivity to insulin-like growth factor receptor-1 inhibition. Cancer Res. 2009;69:1951-1957.

24. Duronio V. The life of a cell: apoptosis regulation by the PI3K/PKB pathway. Biochem J. 2008;415:333-344.

25. Sabatini DM, Sarbassov DD. Phosphorylation and regulation of Akt/PKB by the rictor-mTOR complex. Am Assoc Advanc Sci. 2011: 1098-1101.

26. Roy HK, Olusola BF, Clemens DL, et al. AKT proto-oncogene overexpression is an early event during sporadic colon carcinogenesis. Carcinogenesis. 2002;23:201.

27. Courtney KD, Corcoran RB, Engelman JA. The PI3K pathway as drug target in human cancer. J Clin Oncol. 2010;28:1075-1083.

28. Fumarola C, Bonelli MA, Petronini PG, Alfieri RR. Targeting $\mathrm{PI} 3 \mathrm{~K} / \mathrm{AKT} / \mathrm{mTOR}$ pathway in non small cell lung cancer. Biochem Pharmacol. 2014;90:197-207.

29. Moon Du G, Lee SE, OH MM, et al. NVP-BEZ235, a dual PI3K/mTOR inhibitor synergistically potentiates the antitumor effects of cisplatin in bladder cancer cells. Int J Oncol. 2014;45:1027-1035.

30. Garcia JA, Danielpour D. Mammalian target of rapamycin inhibition as a therapeutic strategy in the management of urologic malignancies. Mol Cancer Ther. 2008;7:1347-1354.

31. Cebulla J, Huuse EM, Pettersen K, et al. MRI reveals the in vivo cellular and vascular response to BEZ235 in ovarian cancer xenografts with different PI3-kinase pathway activity. Br J Cancer. 2015;112:504-513.

32. Danielsen SA, Eide PW, Nesbakken A, Guren T, Leithe E, Lothe RA. Portrait of the PI3K/AKT pathway in colorectal cancer. Biochim Biophys Acta. 2015;1855:104-121.

33. Papadatos-Pastos D, Rabbie R, Ross P, Sarker D. The role of the PI3K pathway in colorectal cancer. Crit Rev Oncol Hematol. 2015; 94:18-30.

34. Hong SW, Shin JS, Moon JH, et al. NVP-BEZ235, a dual PI3K/mTOR inhibitor, induces cell death through alternate routes in prostate cancer cells depending on the PTEN genotype. Apoptosis. 2014;19:895.

35. Hong Z, Li L, Carcedo IG, Zhi PX, Monteiro M, Gu W. Synergistic inhibition of colon cancer cell growth with nanoemulsion-loaded paclitaxel and PI3K/mTOR dual inhibitor BEZ235 through apoptosis. Int J Nanomedicine. 2016;11:1947-1958.

36. Cakir E, Yilmaz A, Demirag F, et al. Prognostic significance of micropapillary pattern in lung adenocarcinoma and expression of apoptosis-related markers: caspase-3, bcl-2, and p53. APMIS. 2011;119: 574-580.

37. Malla RR, Gopinath S, Alapati K, Gorantla B, Gondi CS, Rao JS. uPAR and cathepsin B inhibition enhanced radiation-induced apoptosis in glioma initiating cells. Neuro Oncol. 2012;14:745-760.

38. Soares NDCP, Teodoro AJ, Oliveira FL, et al. Lycopene induce apoptosis in human prostate cells and alters the expression of Bax and Bcl-2 genes. LWT Food Sci Technol. 2014;59:1290-1297.

39. Liu G, Wang T, Wang T, Song J, Zhou Z. Effects of apoptosis-related proteins caspase-3, Bax and Bcl-2 on cerebral ischemia rats. Biomed Rep. 2013;1:861-867.

40. O'Connor L, Huang DC, O'Reilly LA, Strasser A. Apoptosis and cell division: commentary. Curr Opin Cell Biol. 2000;12:257-263. 


\section{Publish your work in this journal}

OncoTargets and Therapy is an international, peer-reviewed, open access journal focusing on the pathological basis of all cancers, potential targets for therapy and treatment protocols employed to improve the management of cancer patients. The journal also focuses on the impact of management programs and new therapeutic agents and protocols on

patient perspectives such as quality of life, adherence and satisfaction. The manuscript management system is completely online and includes a very quick and fair peer-review system, which is all easy to use. Visit http://www.dovepress.com/testimonials.php to read real quotes from published authors.

Submit your manuscript here: http://www.dovepress.com/oncotargets-and-therapy-journal 